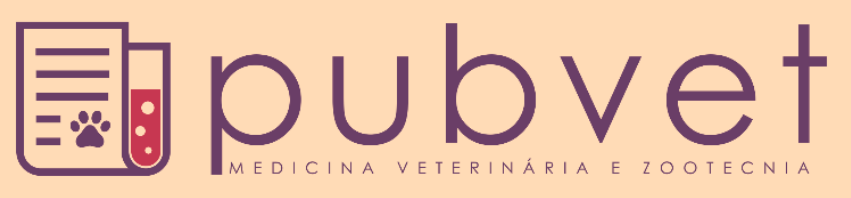

https://doi.org/10.31533/pubvet.v13n01a245.1-8

\title{
Uso de soro autólogo como adjuvante no tratamento de úlcera de córnea em equino: Relato de caso
}

\author{
Matheus Batista de Oliveira ${ }^{1 *}$, Renata Souza Santos ${ }^{1}$, Raúl Fábio Freire Brandão ${ }^{1}{ }^{\bullet}$, José \\ Mateus dos Reis Pinho Araújo ${ }^{2}{ }^{\ominus}$, Gabriel José Moura Fraga ${ }^{3}$, Carla Maria Vela Ulian ${ }^{4}$, \\ Heder Nunes Ferreira ${ }^{4} \theta$
}

${ }^{1}$ Graduando em Medicina Veterinária, Faculdade Pio Décimo, Aracaju - SE, Brasil.

${ }^{2}$ Médico Veterinário, Hospital Veterinário Dr. Vicente Borelli, Aracaju - SE, Brail.

${ }^{3}$ Médico Veterinário Autônomo, Aracaju - SE, Brasil.

${ }^{4}$ Docente da Faculdade Pio Décimo, Aracaju - SE, Brasil.

*Autor para correspondência: matheusoliveiravet@gmail.com

Resumo. O presente trabalho relata o uso do soro autólogo como adjuvante no tratamento de úlcera de córnea de equinos. No dia 08/09/2018 foi atendido no Hospital Veterinário Dr. Vicente Borelli, um equino macho, Quarto de Milha, quatro anos de idade, pesando 460 $\mathrm{kg}$, submetido à uma dieta diária composta de $5 \mathrm{~kg}$ de concentrado e volumoso e água $\mathrm{ad}$ libitum. $\mathrm{O}$ animal participou de prova equestre, transportado em um veículo fechado (caminhão). Assim que retornou à propriedade apresentou desconforto ocular. Solicitou-se o serviço veterinário, que confirmou o diagnóstico para úlcera de córnea e realizou tratamento que não obteve êxito. Na sequência, o animal foi encaminhando ao Hospital Veterinário. No exame clínico geral todos os parâmetros encontravam-se dentro normalidade. Procedeu-se exame clínico oftálmico, identificando blefaroespasmos, irregularidade e opacidade de córnea e câmara anterior, presença de ejeção ciliar, com teste positivo para fluoresceína. Foi iniciado um tratamento sistêmico com administração de Flunixin meglumine durante cinco dias. Dessa forma, para o tratamento tópico foi efetuada a confecção do soro autólogo, colhidos em tubos vermelhos com ativador de coágulos de $5 \mathrm{~mL}$ centrifugados à $3.000 \mathrm{rpm}$. Foram instiladas duas gotas de sulfato de atropina a 1\%/BID nos dias 08/09 e 09/09. Entre os dias 08/09 e 14/09 foi instituído duas gotas de sulfato de tobramicina e soro autólogo a cada uma hora. Nos dias 15/09 e 16/09 a frequência do uso do sulfato de tobramicina e soro autólogo foi de duas horas, totalizando 12 aplicações por dia. Foi procedido um novo teste de fluoresceína notando-se uma redução de aproximadamente $70 \%$. Do dia 17/09 até 20/09 a frequência foi alterada para seis horas entre as aplicações. O teste de fluoresceína foi refeito, o qual se mostrou negativo. No dia 21/09 cessou o uso do soro autólogo, mantendo as aplicações do sulfato de tobramicina até o dia 24/09. Ainda no dia 21/09 foram instiladas duas gotas de diclofenaco de sódio $0,1 \%$, quatro vezes ao dia, até o dia 28/09/2018. Nesse mesmo dia o paciente obteve alta hospitalar. Conclui-se que o soro autólogo atua como adjuvante em úlceras de córnea em equino, conferindo resultados satisfatórios, apresentando baixo custo, praticidade de preparo e minimizando o emprego de tratamentos convencionais sem resposta clínica.

Palavras chave: cavalo, clínica médica, oftalmologia, olho

\section{Use of autologous serum as adjuvant in the treatment of corneal ulcer in horses: Case report}

Abstract. The present study reports the use of autologous serum as adjuvant in the treatment of corneal ulcer in horses. On 09/08/2018 was attended at the Veterinary Hospital Dr. Vicente Borelli, a male equine, Quarter Horse, four years old, weighting $460 \mathrm{~kg}$, 
submitted to a daily diet composed of $5 \mathrm{~kg}$ of concentrate and bulky and water ad libitum. The animal participated in equestrian test, it was transported in closed vehicle (truck), as soon as returned to the property presented ocular discomfort. Therefore, a veterinary service was requested which confirmed the diagnosis for corneal ulcer and instituted treatment that was not successful and was referred to the Veterinary Hospital. In the general clinical examination all the parameters were within normality. An ophthalmic clinical examination was performed, identifying blepharospasms, irregularity and opacity of the cornea and anterior chamber, presence of ciliary ejection, with a positive test for fluorescein. A systemic treatment with Flunixin meglumine administration was started during five days. Thus, the topical treatment with autologous serum was made, collected in red tubes with clot activator of $5 \mathrm{~mL}$ centrifuged at $3,000 \mathrm{rpm}$. Two drops of $1 \%$ atropine sulfate/BID were instilled. Between days 09/08 and 09/14 two drops of tobramycin sulfate and autologous serum were instituted every one hour. On 09/15 and 09/16, the frequency of tobramycin sulfate and autologous serum was 2 hours, totaling 12 applications per day. A further fluorescein test was carried out with a reduction of approximately $70 \%$. From $09 / 17$ to 09/20 the frequency was changed to six hours among applications. The fluorescein test was redone at which was negative. On 09/21 the use of autologous serum was ceased, maintaining the applications of tobramycin sulfate until 09/24. Also on 09/21 two drops of diclofenac sodium $0.1 \%$ were instilled four times a day until 09/28/2018. That same day the patient was discharged. It is concluded that autologous serum acts as an adjuvant in corneal ulcers in horses, conferring satisfactory results, presenting low cost, practicality of preparation and minimizing the use of conventional treatments without clinical response.

Keywords: horse, medical clinic, ophthalmology, eye

\section{Uso del suero autólogo como adyuvante en el tratamiento de úlcera de córnea en equino: Reporte de un caso}

Resumen. El presente trabajo relata el uso del suero autólogo como adyuvante en el tratamiento de úlcera de córnea en equino. En el dia 08/09/2018, fue atendido en el Hospital Veterinario Dr. Vicente Borelli, un equino macho, Cuarto de Milla, con edad de cuatro años, pesando $460 \mathrm{Kg}$, sometido a una dieta diaria compuesta de $5 \mathrm{Kg}$ de concentrado y fibroso y agua ad libitum. El animal participó de prueba ecuestre, transportado en vehículo cerrado (camión), así que retornó a la propiedad presentó incomodidad ocular. Se solicitó servicio veterinario, que confirmó el diagnóstico para úlcera de córnea e instituyó tratamiento que no obtuvo éxito, encaminando al Hospital Veterinario. En el examen clínico general todos los parámetros se encontraban dentro de la normalidad. Se realizó un examen clínico oftálmico, identificando blefaroespasmos, irregularidad y opacidad de córnea y cámara anterior, presencia de eyección ciliar, con prueba positiva para fluoresceína. Se inició un tratamiento sistémico con la administración de Flunixin meglumine durante cinco días. Se instilaron dos gotas de sulfato de atropina al 1\% / BID en los días 08/09 y 09/09. Entre los días 08/09 y 14/09 se instituyeron dos gotas de sulfato de tobramicina y suero autólogo cada hora. En los días 15/09 y 16/09 la frecuencia del uso del sulfato de tobramicina y suero autólogo fue de dos horas, totalizando 12 aplicaciones por día. Se procedió a una nueva prueba de fluoresceína, observándose una reducción de aproximadamente el 70\%. Del día 17/09 a 20/09 la frecuencia se cambió para seis horas entre las aplicaciones. La prueba de fluoresceína fue rehecha, la cual se mostró negativa. El día 21/09 cesó el uso del suero autólogo, manteniendo las aplicaciones del sulfato de tobramicina hasta el día 24/09. En el día 21/09 fueron instiladas dos gotas de diclofenaco de sodio $0,1 \%$, cuatro veces al día, hasta el día 28/09/2018. En ese mismo día el paciente obtuvo alta hospitalaria. Se concluye que el suero autólogo actúa como adyuvante en úlceras de córnea en equino, dando resultados satisfactorios, presentando bajo costo, practicidad de preparación y minimizando el empleo de tratamientos convencionales sin respuesta clínica.

Palabras clave: caballo, clínica médica, oftalmología, ojo 


\section{Introdução}

A úlcera de córnea é uma desordem importante nos olhos equinos, podendo levar à cegueira se não tratada adequadamente (Fusco et al., 2007). São caracterizadas por inúmeras etiologias e patogenias distintas, afetando à integridade da visão em diferentes graus. Na tentativa de buscar um colírio com ausência de conservantes nocivos aos olhos, que Fox et al., (1984) descreveram pela primeira vez a utilização do soro autólogo (AS) em doenças oculares.

A utilização do SA em oftalmologia surgiu da necessidade de encontrar substitutos lacrimais que, além de umidificar, são capazes de fornecer outros componentes da lágrima que são reduzidos em casos de olho seco (López-García et al., 2007). A determinação da resolução da doença varia conforme a etiologia, o comprometimento da estrutura ocular, gravidade da lesão e o tratamento empregado.

A busca por melhores tratamentos oftalmológicos alternativos em patologias como as úlceras de córneas vêm crescendo bastante nas últimas décadas (Ribeiro et al., 2017), devido uma necessidade constante de tratamentos que sejam eficientes, apresentem um baixo custo e concedam uma resposta terapêutica satisfatória. O tratamento convencional muitas vezes não oferece resolução da doença, além de possuir inúmeros efeitos adversos, prejudicando efetivamente a condição oftálmica do paciente.

O SA tem sido amplamente utilizado na rotina clínica de oftalmologistas veterinários, exibindo resultados positivos para o tratamento de úlcera de córneas, essencialmente por apresentar semelhança com a lágrima fisiológica, simulando seus efeitos nos olhos dos animais, atuando em desordens oculares como defeitos epiteliais persistentes e ceratite seca intratável com a terapia convencional (Geerling \& Hartwig 2004).

O objetivo desse trabalho é relatar a utilização do soro autólogo como adjuvante no tratamento de úlcera de córnea em equino.

\section{Relato de caso}

Foi atendido no Hospital Veterinário Dr. Vicente Borelli (HVVB), situado em Aracaju - Sergipe, no dia 08/09/2018, um equino macho, Quarto de Milha (QM), quatro anos de idade, pesando $460 \mathrm{~kg}$, submetido à uma dieta diária composta de $5 \mathrm{~kg}$ de concentrado e volumoso e água ad libitum.

O animal participou de prova equestre, sendo transportado em veículo fechado (caminhão) para o local da prova. Assim que retornou à propriedade apresentou desconforto ocular, foi solicitado serviço veterinário, que estabeleceu suspeita clínica para úlcera de córnea e instituiu tratamento que não obteve êxito, sendo encaminhado ao HVVB. Foi realizado exame clínico geral e específico do sistema oftálmico. No exame clínico geral todos os parâmetros encontravam-se dentro normalidade fisiológica para espécie.

Procedeu-se exame clínico oftálmico, identificando blefaroespasmos, irregularidade e opacidade de córnea e câmara anterior, presença de ejeção ciliar, com teste positivo para fluoresceína (figura 1). Após estabelecimento da suspeita clínica e diagnóstico para úlcera de córnea, foi iniciado o tratamento do paciente.

Para o tratamento sistêmico foi administrado Flunixin meglumine $(1,08 \mathrm{mg} / \mathrm{kg}$, SID, IM) durante cinco dias. No tratamento tópico foi efetuada a confecção do SA, sendo colhidos em tubos com ativador de coágulos de $5 \mathrm{~mL}$ centrifugados em $3.000 \mathrm{rpm}$. Foram instiladas duas gotas de sulfato de atropina a 1\%/BID. Entre os dias 08/09 e 14/09 foi instituído duas gotas de sulfato de tobramicina e soro autólogo a cada uma hora. Nos dias 15/09 e 16/09 a frequência do uso do sulfato de tobramicina e do soro autólogo foi de duas horas, totalizando 12 aplicações por dia. Foi procedido um novo teste de fluoresceína notando-se uma redução de aproximadamente 70\% do quadro. Do dia 17/09 até 20/09 a frequência foi alterada para seis horas entre as aplicações. O teste de fluoresceína foi refeito, o qual se mostrou negativo. No dia 21/09 cessou o uso do soro autólogo, mantendo as aplicações do sulfato de tobramicina até o dia 24/09. Ainda no dia 21/09 foi preconizada anti-inflamatorioterapia com diclofenaco de sódio $0,1 \%$, instilando duas gotas, quatro vezes ao dia, até o dia 28/09/2018 (Tabela1). Nesse mesmo dia o paciente obteve alta hospitalar. 
Tabela1. Tempo e frequência de aplicação dos fármacos e o soro autólogo como adjuvante no tratamento de úlcera de córnea em equino

\begin{tabular}{|c|c|c|c|c|c|}
\hline Fármaco & Doses & Dias & Data & Frequência de aplicação & Administração \\
\hline Flunixin Meglumine & $1,08 \mathrm{mg} / \mathrm{kg}$ & 5 & 08/09-12/09 & 24 horas & Intramuscular \\
\hline Sulfato de atropina a $0,1 \%$ & 2 gotas & 2 & 08/09-09/09 & 12 horas & Tópica \\
\hline \multirow{3}{*}{ Soro autólogo } & \multirow{3}{*}{2 gotas } & 7 & $08 / 09-14 / 09$ & 1 hora & Tópica \\
\hline & & 2 & $15 / 09-16 / 09$ & 2 horas & Tópica \\
\hline & & 4 & $17 / 09-20 / 09$ & 6 horas & Tópica \\
\hline \multirow{3}{*}{ Sulfato de tobramicina a $0,3 \%$} & \multirow{3}{*}{2 gotas } & 7 & 08/09-14/09 & 1 hora & Tópica \\
\hline & & 2 & $15 / 09-16 / 09$ & 2 horas & Tópica \\
\hline & & 8 & $17 / 09-24 / 09$ & 6 horas & Tópica \\
\hline Diclofenaco de sódio a $0,1 \%$ & 2 gotas & 8 & 21/09-28/09 & 6 horas & Tópica \\
\hline
\end{tabular}

\section{Discussão}

A córnea dos equinos é uma das estruturas oculares mais acometidas por afecções, conforme observado por Reichmann et al., (2008), em pesquisa que verificava a incidência de enfermidades oftalmológicas em equinos de tração, concluíram que estas acometem em maiores proporções a córnea.

O histórico do animal possui grande importância para o diagnóstico das ceratites ulcerativas, como mencionado por Moore \& Champagne (2006), que antes de uma realização minuciosa da história oftalmológica é necessário relatar a espécie, raça, idade, sexo, coloração da pelagem e uso do animal, principalmente relacionado à prática esportiva que o animal desenvolvia; o que pode ter predisposto o acometimento oftálmico. Existem diversos fatores que estão relacionados às doenças oftálmicas em equinos, sobretudo nas ceratites ulcerativas, como traumas, corpo estranho, anormalidades palpebrais dos cílios e aparelho lacrimal, infecções virais e micóticas, deficiências nutricionais, queimaduras químicas e imunopatias (Wouk et al., 2006), não sendo possível caracterizar a etiologia no paciente acometido do relato. Nos pacientes afetados, esses efeitos corneanos são caracterizados por vários graus de blefarospasmo, úlceras de córnea com margens epiteliais não aderentes e cicatrização prolongada da ferida (Lassaline-Utter et al., 2014), evidenciando alguns desses sinais no exame clínico específico do animal.

"A úlcera de córnea pode ser classificada de acordo com a área e profundidade em quatro estágios: o estágio zero representa úlceras superficiais em cicatrização ou estáticas; no estágio um, observa-se uma úlcera superficial menor ou igual a um terço da espessura da córnea; já no estágio dois podem-se constatar úlceras grande profundas atingindo mais de um terço da espessura da córnea, edema moderado a acentuado e infiltrados inflamatórios; e o estágio três evidencia-se a perfuração da córnea" (Pringle 2000), podendo classificar a úlcera do equino acometido em grau três. O tratamento é determinante na resolução das úlceras de córnea em equinos, pois quando não tratada pode resultar em necrose progressiva, ulceração estromal profunda, fibrose estromal, ruptura do olho com formação de estafiloma, endoftalmite e phithsis bulbi acarretando a cegueira (Matthews 1994; Moore et al., 1995). Para Moore \& Champagne (2006), blefarospasmo, epífora, fotofobia, opacidades e hiperestesia periocular são sinais de dor ocular, corroborando com o apresentado pelo paciente.

A busca por recursos alternativos para o tratamento das oftalmopatias na medicina veterinária é uma prática constante, como observado por Marfe et al., (2012) que a utilização de células troncos autólogas consiste em uma medida eficiente em úlceras de córneas não responsivas aos tratamentos convencionais, indicando o grande potencial de terapia com células-tronco do sangue periférico.

O SA não contém conservantes, o que evita o risco de toxicidade preservativa, entretanto, existe um risco potencial de induzir infecções devido à contaminação microbiana do frasco conta-gotas (Lee \& Chen 2008), apesar do risco de contaminação cruzada, o SA é uma ferramenta terapêutica eficiente como adjuvante proporcionado uma resposta positiva da condição clínica da úlcera de córnea, como notado no animal. A terapia de escolha baseia-se nos sinais clínicos, nas experiências do veterinário, nos esforços a serem feitos pelo proprietário e nos aspectos financeiros (Brünott et al., 2007), em função da eminência de uma terapia intensiva em ambiente hospitalar, a qual foi requisitada pelo profissional do atendimento inicial, apesar do valor imputado para o internamento e condições afins. 
O tratamento com SA é um método eficiente para fornecer um número de fatores de crescimento que foram reduzidos por distúrbios da superfície ocular. Existem algumas evidências médicas de que o SA pode ser clinicamente eficaz em algumas doenças da superfície ocular em comparação com o tratamento padrão (Quinto et al., 2008), conforme observado após a utilização do SA, uma diminuição do aspecto ulcerativo, além de teste de fluoresceína negativo (Figura 2). A busca de componentes biológicos é uma alternativa viável para a utilização na rotina da oftalmologia em equinos, destacando-se as plaquetas que são um grande reservatório de fatores de crescimento e moléculas de adesão tecidual entre outras, desempenhando assim um papel claramente preponderante no reparo do dano tecidual (Alio et al., 2007), aspectos determinantes para a instituição do tratamento usando o SA como adjuvante. A preparação SA não acarreta dificuldades técnicas e é relativamente custo-efetivo, pois os hospitais geralmente possuem a tecnologia necessária para sua preparação (centrífuga) (Geerling \& Hartwig 2004), ou até mesmo por decantação do sangue, obtendo-se o plasma.

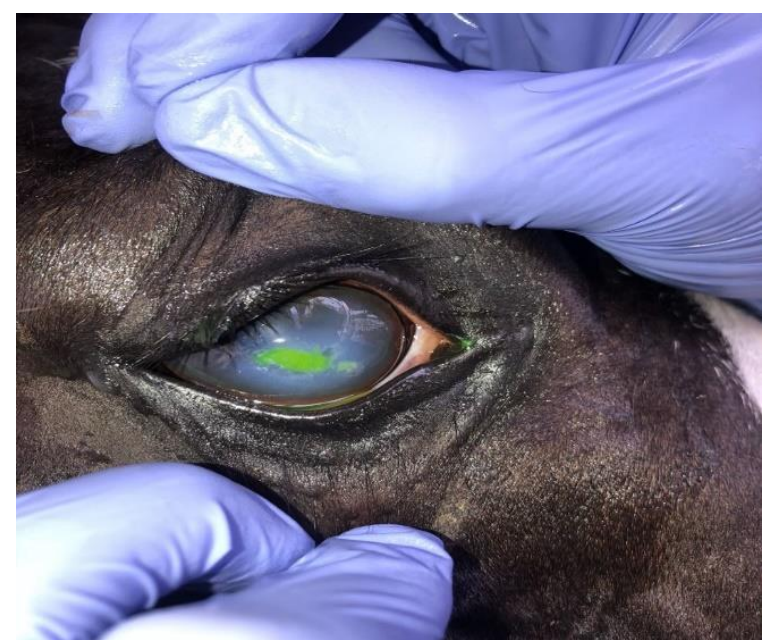

Figura 1. Teste de fluoresceína positivo no dia 08/09/2018 em olho direito com úlcera de córnea.

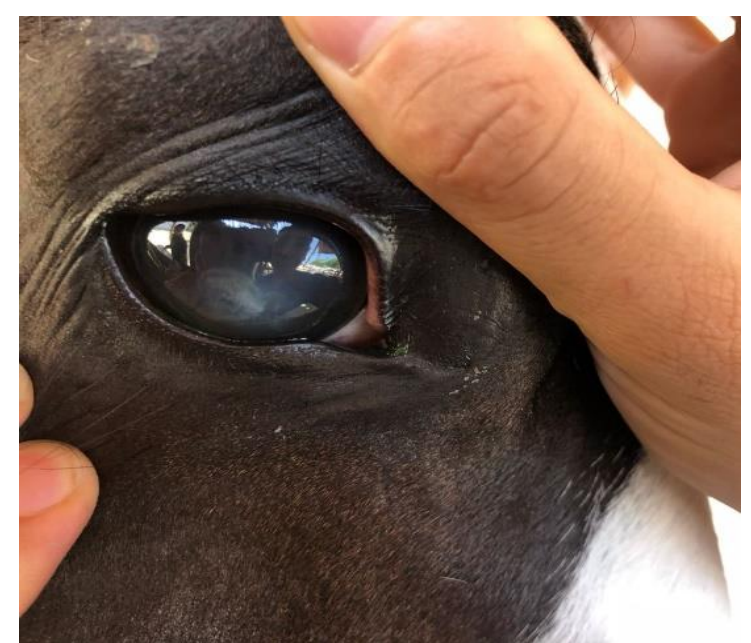

Figura 2. Diminuição da úlcera de córnea após 15 dias de tratamento, com teste fluoresceína negativo.

Para Zhou \& Beuerman (2012) "as lágrimas e o soro contêm abundantes fatores de crescimento e componentes antibacterianos em comum, que possibilitam os fatores nutricionais necessários para manter a viabilidade celular no processo de reparação epitelial", hipotetizando-se essa similaridade que pesquisas têm sido direcionadas para identificar às respostas das oftalmopatias com esse modelo de tratamento. Os fatores de crescimento têm se mostrado eficazes no tratamento de doenças corneanas imunes e degenerativas em humanos (Lambiase et al., 2012), podendo haver efeitos também em cavalos (Knickelbein et al., 2018). Nesse sentido, o Epitelial Grow Factor (EGF/Fator de Crescimento Epitelial) acelera o processo de migração de células epiteliais e tem efeitos antiapoptóticos. Este fator está presente tanto na secreção lacrimal basal quanto na reflexa, com uma concentração ligeiramente inferior à do AS. O TGF-b (Transforming Growth Factor beta) está envolvido nos processos de reparo epitelial e estromal lloyd (Wilson et al., 1991), com concentração no soro três vezes maior que a concentração encontrada em lágrimas.

O sulfato de atropina pode diminuir o ângulo de drenagem do humor aquoso e a dor ocular, onde o tratamento não pode exceder 15 dias, pois pode causar diminuição da secreção lacrimal e induzir uma ceratoconjuntivite seca, indicando uma gota no máximo três vezes ao dia (Andrade et al., 2008) concordando com a terapêutica utilizada, sendo usada BID durante dois dias. Existem diversos protocolos que são normalmente utilizados em úlceras de córneas, variando de acordo com o princípio ativo, às características das lesões e inerentes à resposta de cada animal. Outras formas de tratamentos podem ser empregadas, conforme Wouk et al., (2006) analisando o uso de sulfato de condroitina "A" e ciprofloxacino em úlceras de córneas induzidas experimentalmente, verificaram que a instilação tópica promove a cicatrização mais rápida, além de evitar a formação de cicatriz corneana e reduzir as manifestações oculares de origem inflamatória, podendo ser um recurso terapêutico complementar na rotina da oftalmologia veterinária. Com base no uso do SA em humanos, Noble et al., (2004) afirmam que se deve ter cuidado, porque nem todos os pacientes podem ser tratados devido às dificuldades 
sistêmicas e, em algumas ocasiões, é necessário fornecer um suplemento de sulfato de ferro para prevenir a anemia.

Não foi observado efeitos adversos decorrentes do uso do SA, porém, Ogawa et al., (2003) observaram em humanos que pode haver deposição de imunoglobulinas no local da lesão, os pacientes podem experimentar desconforto aumentado, epiteliopatia leve, conjuntivite bacteriana ou eczema da pálpebra. Pan et al., (2013) relataram que utilização de SA em humanos é frequente, sendo reportado melhora do desconforto de lesões oftálmicas, apresentando boa tolerância, apesar da não descrição de efeitos adversos em equinos. Seu uso na rotina médica humana é descrito, desde que usado com segurança em ambiente ambulatorial e de internação, sob um rígido protocolo de preparação e armazenamento (Lagnado et al., 2004; Partal \& Scott 2011) o que ainda não é uma realidade na medicina veterinária, sendo seu preparo e armazenamento realizados empiricamente.

A idade pode estar relacionada com epidemiologia da doença, uma vez que em pacientes caninos, a ulceração corneana crônica parece ser uma doença de pacientes de meia-idade a idosos, com uma idade média de 14,7 anos (Lassaline-Utter et al., 2014). Estudos anteriores não mensuram a concentração dos componentes biologicamente ativos no SA, é possível que a concentração do EGF e do TGF- $\beta$ ou outros fatores biológicos pode ser diferente entre os estudos incluídos devido à variação nas rpm usadas em centrifugação (Pan et al., 2013). Como a o SA é um fluido corporal, é capaz de transmitir infecções. Outra desvantagem do tratamento do SA reside nas frequentes extrações de sangue, principalmente nos grupos que requerem tratamento prolongado. Nesses casos, é importante atentar, pois nem todos os pacientes podem ser tratados por dificuldades sistêmicas e, em algumas ocasiões, é necessário fornecer um suplemento de sulfato de ferro para prevenir a anemia (López-García et al., 2007).

Quanto a contaminação microbiológica, em cultura bacteriana provenientes do SA de amostras de humanos, Leite et al., (2006) observaram que "após 30 dias de uso pelos pacientes, foram contaminadas por microrganismos simples ou múltiplos, tais como: Klebsiella pneumoniae, Streptococcus viridans, Candida sp., Pseudomonas aeruginosa, Bacillus sp, Staphylococcus aureus, Micrococcus sp.," ressaltando-se os cuidados para o acondicionamento e armazenamento das amostras, assim como correta manipulação. Ollivier et al., (2004) analisando a ação das metaloproteinases nas úlceras de córneas, concluíram que tratamentos médicos e cirúrgicos das úlceras de córnea nos equinos levam a uma redução na atividade proteolítica do filme lacrimal que corresponde à melhora dos sinais clínicos de ulceração corneana, corroborando com tratamento clínico utilizado e seu o efeito observado no animal.

\section{Conclusão}

Conclui-se que o SA atua como adjuvante em úlceras de córnea em equino, conferindo resultados satisfatórios, apresentando baixo custo, praticidade de preparo e minimizando o emprego de tratamentos convencionais sem resposta clínica.

\section{Referências Bibliográficas}

Alio J.L., Abad M., Artola A., Rodriguez-Prats J.L., Pastor S. \& Ruiz-Colecha J. (2007). Use of autologous platelet-rich plasma in the treatment of dormant corneal ulcers. Ophthalmology 114, 1286-1293.

Andrade S.F., Giuffrida R. \& Ribeiro M.G. (2008). Quimioterápicos antimicrobianos e antibióticos. In: Manual de terapêutica veterinária (ed. by Andrade SF), pp. 26-72. Roca, São Paulo, Brasil.

Brünott A., Boevé M.H. \& Velden M.A. (2007). Grid keratotomy as a treatment for superficial nonhealing corneal ulcers in 10 horses. Veterinary Ophthalmology 10, 162-167.

Fox R.I., Chan R., Michelson J.B., Belmont J.B. \& Michelson P.E. (1984) Beneficial effect of artificial tears made with autologous serum in patients with keratoconjunctivitis sicca. Arthritis \& Rheumatism 27, 459-461.

Fusco M.A., Vieira J.B., Ramos M.T. \& Pires N.R. (2007). Resultados de testes de cultura e antibiograma em seis casos de úlcera corneana em equinos. Archives of Veterinary Science 12, 5659. 
Geerling G. \& Hartwig D. (2004). Autologous serum-eye-drops for ocular surface disorders. A literature review and recommendations for their application. Der Ophthalmologe: Zeitschrift der Deutschen Ophthalmologischen Gesellschaft 99, 949-959.

Knickelbein K.E., Scherrer N.M. \& Lassaline M. (2018). Corneal sensitivity and tear production in 108 horses with ocular disease. Veterinary Ophthalmology 21, 76-81.

Lagnado R., King A.J., Donald F. \& Dua H.S. (2004). A protocol for low contamination risk of autologous serum drops in the management of ocular surface disorders. British Journal of Ophthalmology 88, 464-465.

Lambiase A., Sacchetti M. \& Bonini S. (2012). Nerve growth factor therapy for corneal disease. Current Opinion in Ophthalmology 23, 296-302.

Lassaline-Utter M., Cutler T.J., Michau T.M. \& Nunnery C.M. (2014). Treatment of nonhealing corneal ulcers in 60 horses with diamond burr debridement (2010-2013). Veterinary Ophthalmology 17, 76-81.

Lee G.A. \& Chen S.X. (2008). Autologous serum in the management of recalcitrant dry eye syndrome. Clinical \& experimental Ophthalmology 36, 119-122.

Leite S.C., Castro R.S., Alves M., Cunha D.A., Correa M.E.P., Silveira L.A., Vigorito A.C., Souza C.A. \& Rocha E.M. (2006). Risk factors and characteristics of ocular complications, and efficacy of autologous serum tears after haematopoietic progenitor cell transplantation. Bone Marrow Transplantation 38, 223-227.

López-García J.S., Garcia-Lozano I., Rivas L. \& Martinez G.J. (2007). Use of autologous serum in ophthalmic practice. Archivos de la Sociedad Espanola de Oftalmologia 82, 9-20.

Marfe G., Massaro-Giordano M., Ranalli M., Cozzoli E., Di Stefano C., Malafoglia V., Polettini M. \& Gambacurta A. (2012). Blood derived stem cells: an ameliorative therapy in veterinary ophthalmology. Journal of cellular physiology 227, 1250-1256.

Matthews A.G. (1994). The etiopathogenesis of infectious keratitis in the horse. Equine Veterinary Journal 26, 432-433.

Moore C.P. \& Champagne E. (2006). Doenças do olho. In: Medicina interna de grandes animais. $3^{a}$ ed. Barueri: Manoli, 2006. Cap. 37. p.1149-1158 . (ed. by Smith BP), pp. 1149-1158 . Manoli, Barueri, São Paulo, Brasil.

Moore C.P., Collins B.K. \& Fales W.H. (1995). Antibacterial susceptibility patterns for microbial isolates associated with infectious keratitis in horses: 63 cases (1986-1994). Journal of the American Veterinary Medical Association 207, 928-933.

Noble B.A., Loh R.S.K., MacLennan S., Pesudovs K., Reynolds A., Bridges L.R., Burr J., Stewart O. \& Quereshi S. (2004) Comparison of autologous serum eye drops with conventional therapy in a randomised controlled crossover trial for ocular surface disease. British Journal of Ophthalmology $88,647-652$.

Ogawa Y., Okamoto S., Mori T., Yamada M., Mashima Y., Watanabe R., Kuwana M., Tsubota K., Ikeda Y. \& Oguchi Y. (2003).Autologous serum eye drops for the treatment of severe dry eye in patients with chronic graft-versus-host disease. Bone Marrow Transplantation 31, 579-583.

Ollivier F.J., Brooks D.E., Van Setten G.B., Schultz G.S., Gelatt K.N., Stevens G.R., Blalock T.D., Andrew S.E., Komaromy A.M. \& Lassaline M.E. (2004). Profiles of matrix metalloproteinase activity in equine tear fluid during corneal healing in 10 horses with ulcerative keratitis. Veterinary Ophthalmology 7, 397-405.

Pan Q., Angelina A., Zambrano A., Marrone M., Stark W.J., Heflin T., Tang L. \& Akpek E.K. (2013). Autologous serum eye drops for dry eye. The Cochrane database of systematic reviews 22, 61-66.

Partal A. \& Scott E. (2011). Low-cost protocol for the production of autologous serum eye drops by blood collection and processing centres for the treatment of ocular surface diseases. Transfusion Medicine 21, 271-277.

Pringle J. (2000). Distúrbios oftalmicos. In: Medicina Interna de grandes animais (ed. by Ogilvie TH), pp. 295 - 304. Artes Medicas Sul, Porto Alegre, Rio Grande do Sul, Brasil.

Quinto G.G., Campos M. \& Behrens A. (2008). Autologous serum for ocular surface diseases. Arquivos brasileiros de oftalmologia 71, 47-54. 
Reichmann P., Oliveira Dearo A.C. \& Rodrigues T.C. (2008). Ocorrência de doenças oftalmológicas em eqüinos utilizados para tração urbana na cidade de Londrina, PR. Ciência Rural 38, 2525-2528.

Ribeiro M.V.M.R., Melo V.F., Barbosa M.E.F.C., Tozzi M.U.F., Ramos M.S.B., Gaia N.M.S.R.S., Santos V.M.G., Neri W.O., Barbosa F.T. \& Ribeiro E.A.N. (2017). The use of platelet rich-plasma in ophthalmology: a literature review. Revista Brasileira de Oftalmologia 76, 319-324.

Wilson S.E., Lloyd S.A. \& Kennedy R.H. (1991). Basic fibroblast growth factor (FGFb) and epidermal growth factor (EGF) receptor messenger RNA production in human lacrimal gland. Investigative Ophthalmology \& Visual Science 32, 2816-2820.

Wouk A.F., Ulian I., Muller G. \& Souza A.L.G. (2006). Action of chondroitin sulfate sssociate to the ciprofloxacin corneal ulcers in horses. Revista Acadêmica Ciência Animal 4, 11-20.

Zhou L. \& Beuerman R.W. (2012). Tear analysis in ocular surface diseases. Progress in Retinal and Eye Research 31, 527-550.

Recebido: 18 novembro, 2018.

Aprovado: 10 dezembro, 2018.

Publicado: 14 janeiro, 2019.

Licenciamento: Este artigo é publicado na modalidade Acesso Aberto sob a licença Creative Commons Atribuição 4.0 (CCBY 4.0), a qual permite uso irrestrito, distribuição, reprodução em qualquer meio, desde que o autor e a fonte sejam devidamente creditados. 